\title{
A New Vision to Efficacy, Comparative Effectiveness and Cost-Effectiveness Research in Nursing
}

\author{
Nargess Ramazanzadeh ${ }^{1}$, Leila Valizadeh ${ }^{2}$, Vahid Zamanzadeh ${ }^{3}$ and Samaneh Alizadeh ${ }^{4 *}$ \\ ${ }^{1}$ Department of Medical-Surgical Nursing, Student Research Committee, Faculty of Nursing \& Midwifery, Tabriz University of \\ Medical Sciences, Tabriz, Iran \\ ${ }^{2}$ Department of Pediatric Nursing, Faculty of Nursing and Midwifery, Tabriz University of Medical Sciences, Tabriz, Iran \\ ${ }^{3}$ Department of Medical-Surgical Nursing, Faculty of Nursing and Midwifery, Tabriz University of Medical Sciences, Tabriz, Iran \\ ${ }^{4}$ Department of Medical-Surgical Nursing, Student Research Committee, Faculty of Nursing \& Midwifery, Tabriz University of \\ Medical Sciences, Tabriz, Iran \\ *Corresponding author: Samaneh Alizadeh, Faculty of Nursing \& Midwifery, Tabriz University of Medical Sciences, Tabriz, Iran
}

ARTICLE INFO

Received: 㓞 December 01, 2021

Published: 幽 December 16, 2021

Citation: Nargess Ramazanzadeh, Leila Valizadeh, Vahid Zamanzadeh, Samaneh Alizadeh. A New Vision to Efficacy, Comparative Effectiveness and Cost-Effectiveness Research in Nursing. Biomed J Sci \& Tech Res 40(4)-2021. BJSTR. MS.ID.006475.

Abbreviations: FCC: Federal Coordinating Council; IOM: Institute of Medicine of The National Academies; ARRA: American Recovery and Reinvestment Act; ACA: Affordable Care Act; DNP: Doctor of Nursing Practice

\section{ABSTRACT}

Background: The important role of research in nursing professional development increases the considerations to comparing clinical interventions, because they generate nursing evidence and knowledge.

Objectives: The purpose of this study was to determine a new vision to efficacy, comparative effectiveness and cost-effectiveness research in nursing.

Design: An integrative review and Delphi technique in combination.

Methods: Twenty-four papers enrolled to the review over 17102 initial papers from Science Direct, PubMed and Google Scholar databases from 2000-2021. A one round Delphi technique with 7 nursing experts was conducted to confirm or emphasize on the collected data in the review.

Results: The review resulted in the characteristics of efficacy, comparative effectiveness and cost-effectiveness research. Also nursing experts mentioned the importance and existing obstacles to conduct effectiveness studies.

Conclusion: The main conclusion of conducting efficacy and effectiveness research which produces complementary evidence is the reduction of the gap between theory and practice in nursing and its professional development.

Keywords: Efficacy; Comparative Effectiveness; Cost-Effectiveness

\section{Introduction}

Research possesses an important role in nursing practice development which can provide an opportunity to develop new knowledge and improve nursing care [1]. Recently, there is an increased focus on research conducted to compare clinical approaches [2]. Because the results of these studies are more patient-centred and generalizable [3]. Also nursing profession requires knowledge transfer from research to clinic [4] in order to utilize the obtained evidence regarding to implementations and interventions in practice. An important aim of clinical interventions research is to respond health care problems or needs of patients. Which can lead to produce clinical evidence and knowledge by identifying the effectiveness of the desired intervention [5]. However, nursing research activities have fewer focus on development of nursing interventions, while finding effective solutions to patient 
problems should be the primary motivation of nursing and its research community [5]. Therefore, it is necessary to mention on a more detailed information rather than effectiveness itself, that in which individuals and what circumstances the intervention is effective. Because it can develop clinical knowledge produced by interventions research and increase the level of theoretical knowledge related to different interventions [5].

In this study, two types of research that compares implementations, interventions and nursing cares, are referred to as efficacy and effectiveness research. They are both classified as intervention-based research that determine the impact of an intervention [6]. The two fundamental words of efficacy and effectiveness are different and should not be used mistakenly instead of each other [6]. Therefore, the research question determines the type of efficacy or effectiveness studies [2]. In terms of research design, to determine the impact of an intervention descriptive, correlation or observational designs, and to test the efficacy or effectiveness of an intervention the experimental or semi-experimental research designs are appropriate, respectively [6]. And the most used designs are clinical trials [6,7], which are widely welcomed by researchers, policy makers, stakeholders and journals in comparing clinical approaches. In the meantime, comparative effectiveness research and cost-effectiveness research provide opportunities to make change in health care delivery and improve patient outcomes [8]. Therefore, they can be considered as national health policies and provide the opportunity to identify the best evidence-based interventions which works in their target communities and settings [9]. Because the lack of comparative clinical data on effectiveness, costs of treatment, and care delivery models can be a major challenge in optimizing health care value [8]. The purpose of this study was to determine a new vision to efficacy, comparative effectiveness and cost-effectiveness research in nursing by an integrative review and Delphi technique in combination.

\section{Method}

This study was conducted in two phases, an integrated literature review and a Delphi technique to confirm or emphasize on the collected data in the review.

\section{Phase One - Integrative Review}

The framework of Whittemore and Knafl [2005] for integrated reviews was used to conduct the review [10]. This approach allows the review to contain diverse primary research methods, thus provides a comprehensive review needed for the topic of interest [10]. The Science Direct, Pub Med and Google Scholar databases were searched from 2000-2021 to identify the primary papers. The PubMed search strategy was ( (C "Comparative Effectiveness Research"[Mesh]) OR “Cost-Benefit Analysis”[Mesh]) OR ["Treatment Outcome"[Mesh] OR "Therapeutic Equivalency"[Mesh])) AND "Nursing"[Mesh]). In other databases a full search strategy using the following terms were conducted: effectiveness research/study, comparative effectiveness research/ study, cost-effectiveness research/study, efficacy research/study and nursing/nurse led. Inclusion criteria consisted of any research or paper in the nursing field without methodological limitations about efficacy, comparative effectiveness, and cost-effectiveness research, with full text access in English or Persian. To access more papers and keep the maximum amount of data available, the publication time limit was not considered. Critical Appraisal Skills Program checklists were used to assess the quality of included papers [11] for their trustworthiness, relevance and results [12].

Papers were excluded if they were conducted using efficacy or effectiveness methods or a review of studies conducted with these methods, did not explicitly mention their use of these methods, and if they did not address the features of these types of research. The initial search result included 17096 papers and 6 additional records from other sources. Sixty-seven duplicate papers were removed. One of the authors screened the title and abstract of remaining 17033 papers based on inclusion criteria and excluded 16460 papers as irrelevant, abstract only, and inadequate quality. A review full text for eligibility resulted in 548 more excluded papers and 3 papers that were removed following critical appraisal. The outcomes were discussed with other authors at any stage and there was a full agreement with no conflict between them. Finally, 24 papers met the eligibility criteria to include in the integrative review that all were published in English (Figure 1). 


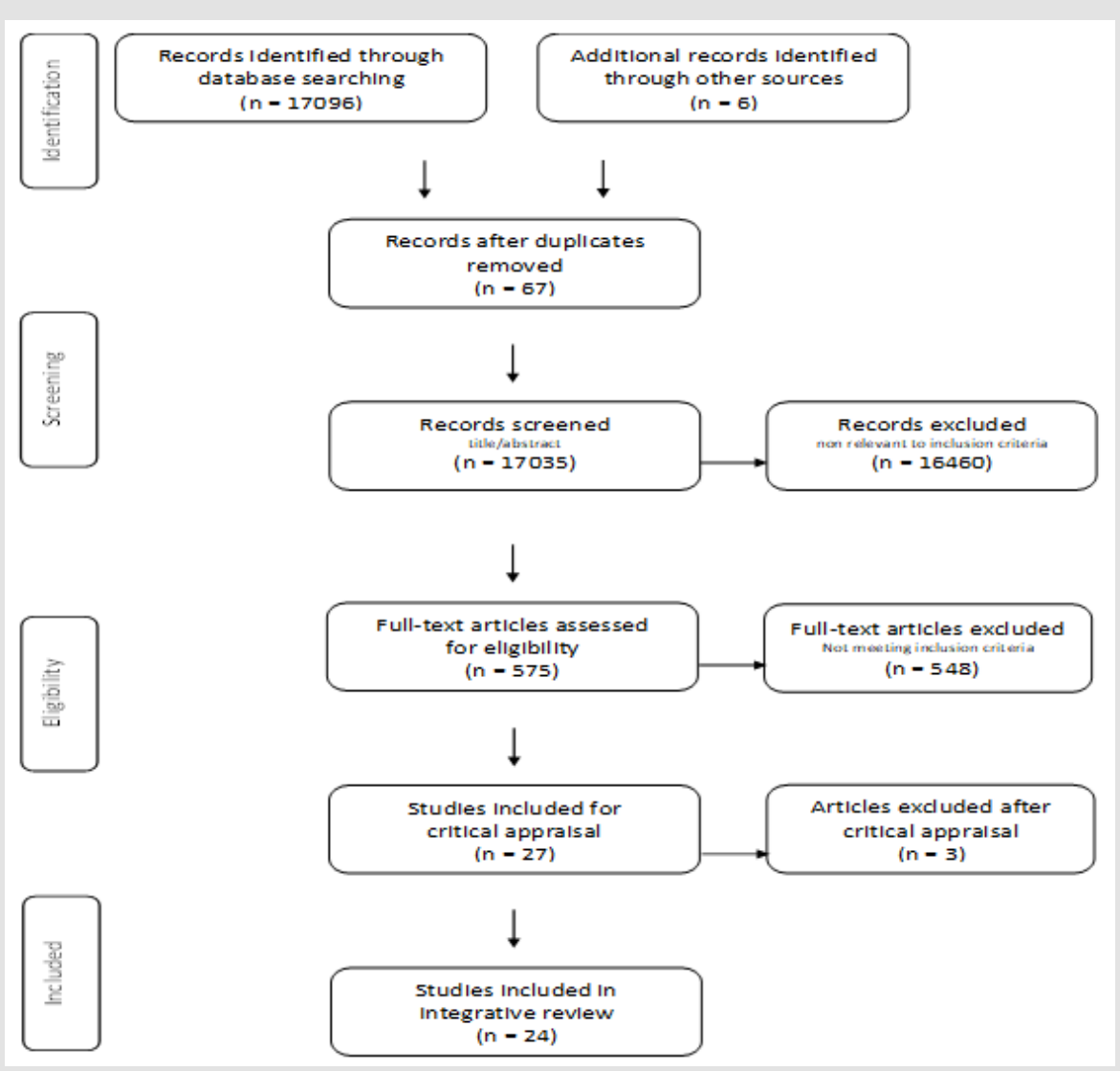

Figure 1: The most feasible position of fetoscope.

\section{Phase Two - Delphi Technique}

As review conducted, a summary of the interested research definitions was prepared and a questionnaire consisting of 10 questions was designed to ask nursing experts about efficacy and effectiveness studies using Delphi technique. The Delphi technique was used to collect a variety of data from nursing experts who were distanced and dispersed throughout Iran, whose perspective to research was very important due to their familiarity with a variety of research methodologies used in nursing studies. Nursing experts including editors in chief of nursing journals and research assistants of their nursing schools were the research population. The list of "Medical Journal Commission" of Iran was used to obtain the nursing journals which resulted in 31 journals. The email addresses of the 3 journals were invalid, so 28 journals were listed. The email address of the editors and research assistants were also searched separately. Finally, 27 editors in chief and 21 research assistants were directly enrolled in the study. Based on snowball sampling method, two international nursing experts with high citation rates who were introduced by one of the participants were included, too. Because the number of nursing experts was limited, all individuals in the research population including a total number of 50 people enrolled in the study. The questionnaire was sent to the journals in two occasions and once directly to editors in chief, the research assistants and two international nursing experts, respectively. The results of Delphi technique were used to confirm or emphasize on extracted data from integrated review of literatures.

\section{Results}

\section{Phase one: Integrative Review}

A total of 24 papers were enrolled in the review including articles, editorials and reports, published in English between 2000 to 2021. The Federal Coordinating Council [FCC] [13] and Institute of Medicine of The National Academies [IOM] [14] reports both were published in 2009. Also, the American Recovery and Reinvestment Act [ARRA] of 2009 and the patient protection and Affordable Care Act [ACA] of 2010 have increased the considerations to comparative effectiveness type studies widely [15], Which resulted in more research conducted in effectiveness scope since 2009. In this integrative review findings are presented based on the research area, objectives, application, significant features, appropriate/ common research design, and the study classification in two tables. (Table 1) [6-7,16-18] indicates a comparison of efficacy and effectiveness studies. (Table 1) [6-7,16-18] Also considering two types of studies in effectiveness research scope that can play an important role in determining health policies at national levels, (Table 2) [6-9,13-14,19-32] presents comparative effectiveness and cost-effectiveness studies separately. 
Table 1: A comparison of Efficacy and Effectiveness Studies.

\begin{tabular}{|c|c|c|}
\hline \multirow{2}{*}{ Desired Dimensions } & \multicolumn{2}{|c|}{ Findings } \\
\hline & Efficacy Study & Effectiveness Study \\
\hline Research Area & $\begin{array}{l}\text { Assessment of an intervention under ideal conditions or } \\
\text { selected situations [16] }\end{array}$ & $\begin{array}{l}\text { Assessment of an intervention under normal conditions of } \\
\text { health care [16] }\end{array}$ \\
\hline Objectives & $\begin{array}{l}\text { Demonstration of the desired result of a drug or procedure } \\
\text { in an ideal setting with stringent study criteria [6] }\end{array}$ & $\begin{array}{l}\text { To test the capability of interventions to make positive } \\
\text { results in the usual or routine clinical care environment [6] } \\
\text { Obtaining patient-centered outcomes [16] }\end{array}$ \\
\hline Application & $\begin{array}{l}\text { Conductible in tertiary and large care settings, referral } \\
\text { centers, where have more specialized clinicians and } \\
\text { technically is better equipped [16] } \\
\text { Conducting in clinical or laboratory settings with } \\
\text { educational trained staff and selective study samples [17] }\end{array}$ & $\begin{array}{l}\text { Assessing interventions effectiveness in the real world, } \\
\text { which has been proved to be efficacious in the ideal settings } \\
\qquad[17] \\
\text { Conducting an intervention by routine personnel with } \\
\text { routine training and routine control instead of placebo [16] }\end{array}$ \\
\hline Application & $\begin{array}{l}\text { Conductible in tertiary and large care settings, referral } \\
\text { centers, where have more specialized clinicians and } \\
\text { technically is better equipped [16] } \\
\text { Conducting in clinical or laboratory settings with } \\
\text { educational trained staff and selective study samples [17] }\end{array}$ & $\begin{array}{l}\text { Assessing interventions effectiveness in the real world, } \\
\text { which has been proved to be efficacious in the ideal settings } \\
\qquad \\
\text { Conducting an intervention by routine personnel with } \\
\text { routine training and routine control instead of placebo [16] }\end{array}$ \\
\hline Significant Features & $\begin{array}{l}\text { Emphasis on internal validity of the study, strict control of } \\
\text { variables, limited sample number, shorter study duration } \\
\text { timing [6] } \\
\text { Offers little insight to adapt the interventions in the real } \\
\text { world and does not provide enough information for clinics } \\
\text { and practice [17] }\end{array}$ & $\begin{array}{l}\text { Emphasis on external validity of the study, more sample } \\
\text { number and longer study duration timing [6] } \\
\text { Sample selection as real population representatives [16] } \\
\text { Conducting with the least exclusion criteria [17] }\end{array}$ \\
\hline $\begin{array}{l}\text { Appropriate/Common } \\
\text { Research Design }\end{array}$ & $\begin{array}{l}\text { Controlled experimental trials and randomized controlled } \\
\text { trials [6] }\end{array}$ & $\begin{array}{l}\text { Clinical trials [7] } \\
\text { Diverse research designs from observational to randomized } \\
{[18]}\end{array}$ \\
\hline Study Classification & $\begin{array}{l}\text { Intervention-based research [6] } \\
\qquad \text { Explanatory trials [16] }\end{array}$ & $\begin{array}{l}\text { Intervention-based research [6] } \\
\text { Pragmatic trials [16] }\end{array}$ \\
\hline
\end{tabular}

\section{Phase Two: Delphi Study}

A total of 7 nursing experts [14\%] participated in this study, including 5 editors in chief, 1 managing editor and 1 executive manager. In spite of follow-ups, other experts did not reply to the e-mails which was justified by the coincidence of data collection period with the second semester's examinations and the limited time of study duration. Therefore, outcomes of the conducted single round Delphi, which resulted in mindful comments and answers of participated experts, was used to confirm or emphasize on extracted data from integrated review of literatures. The Delphi phase data are classified in 6 finding areas about Efficacy, Comparative Effectiveness and Cost-Effectiveness research.

\section{Knowledge of Experts About Efficacy, Comparative Effectiveness and Cost-Effectiveness Research}

The methodology of these three studies is not mentioned explicitly in the curriculum and are not taught in detail, which results in poor knowledge and awareness of students, faculty members and nursing experts about differences and the nature of these studies (Participants No. 6 and 7). “... This lack of knowledge represents a training deficiency for nurses, journals and even the teachers ..." (P.No. 6). On the other hand, the general information of individuals indicates that all three types of research usually take quantitative methods (P.No. 5) and are often conducted as a trial which assesses an impact, so differentiation between them may be difficult ([P.No. 2). Therefore, if the type of study was not explicitly mentioned, regard to the title or inappropriate use of vocabulary due to assessing the impact of an intervention or care, it may mistakenly be considered as effectiveness and usually comparative form of studies, while the underlying nature of the study is efficacy (P.No. 6 and 7). 
Table 2: Comparative Effectiveness and Cost-Effectiveness Studies.

\begin{tabular}{|c|c|c|}
\hline $\begin{array}{l}\text { Desired } \\
\text { Dimensions }\end{array}$ & Comparative Effectiveness Study & Cost-Effectiveness Study \\
\hline Research Area & $\begin{array}{l}\text { Comparing the advantages and disadvantages of various interventions } \\
\text { and strategies regarding to prevention, diagnosis, treatment and health } \\
\text { status control, in real-world setting }[13,14]\end{array}$ & $\begin{array}{l}\text { A comparative analysis of two or more interventions } \\
\text { in their health and economic outcomes [7] }\end{array}$ \\
\hline Objectives & $\begin{array}{l}\text { Improving the health outcomes, developing and disseminating evidence- } \\
\text { based information collected from patients, clinicians and other decision- } \\
\text { makers in response to their expressed needs and health problems }[13,14]\end{array}$ & $\begin{array}{l}\text { Cost reduction and quality improvement of } \\
\text { interventions [19] } \\
\text { Determining the main value of a strategy considering } \\
\text { cost and effectiveness both together [14] }\end{array}$ \\
\hline Application & $\begin{array}{l}\text { Comparing different types of clinical purposes [6] } \\
\text { Focusing on evidence-based care to make informed decisions by patients } \\
\text { and healthcare providers in diverse health environments [14] } \\
\text { Has a special place in health care decision making [20,21] } \\
\text { Providing the best evidence for optimizing patient care [22,23] } \\
\text { Providing an appropriate setting for improving health at the individual } \\
\text { and social levels [24] } \\
\text { Providing patient-centered care with more trustworthiness and } \\
\text { applicability [21,25] } \\
\text { Creating many global opportunities and reducing patient's financial } \\
\text { burden and maintaining their optimal health [26] } \\
\text { Focusing on evidence-based methods provides the opportunity to use } \\
\text { achieved evidences in real clinical environments based on investments } \\
\text { and planning of care providers, patients, and stakeholders [27] } \\
\text { Needs for systematic reviews, with the least bias, to make reliability and } \\
\text { facilitate the use of findings standardly to identify and summarize the } \\
\text { body of available evidence knowledge [28] } \\
\text { Producing scientific knowledge about health interventions by means of } \\
\text { powerful meta-analysis of strong and stable primary studies [29] } \\
\text { Creating a base to conduct implementation researches in order to prove } \\
\text { the usefulness of sufficient, reliable and valuable evidence produced } \\
\text { through comparative effectiveness studies [30] }\end{array}$ & $\begin{array}{l}\text { Examining Direct and Indirect Care Costs [28] } \\
\text { Determining both effectiveness and cost of a } \\
\text { particular and rare care or intervention compared } \\
\text { to routine health care by cost-effectiveness analysis } \\
\text { [8,14,31] } \\
\text { Devoting a part of comprehensive comparative } \\
\text { effectiveness evaluation study to cost effectiveness } \\
\text { research, including economic appraisal tools for } \\
\text { analysis [8]. }\end{array}$ \\
\hline $\begin{array}{l}\text { Significant } \\
\text { Features }\end{array}$ & $\begin{array}{l}\text { Determining which intervention effects the most, on whom, and under } \\
\text { what conditions }[13,14,29] \\
\text { Big data that has large volumes, greater processing speed and a structural } \\
\text { and standard variety [32] } \\
\text { Comparing possible choices and active and ongoing interventions } \\
\text { competitively [22] } \\
\text { More challenging compared to placebo or controlled interventions [22,23] } \\
\text { Necessary to be able for comparison and competition with the } \\
\text { comparator of the desired intervention [22] }\end{array}$ & $\begin{array}{l}\text { Determining which intervention effects the most, on } \\
\text { whom, and under what conditions }[13,14,29] \\
\text { Big data that has large volumes, greater processing } \\
\text { speed and a structural and standard variety [32] } \\
\text { Comparing possible choices and active and ongoing } \\
\text { interventions competitively [22] } \\
\text { More challenging compared to placebo or controlled } \\
\text { interventions [22,23] } \\
\text { Necessary to be able for comparison and competition } \\
\text { with the comparator of the desired intervention [22] }\end{array}$ \\
\hline $\begin{array}{l}\text { Appropriate/ } \\
\text { Common Research } \\
\text { Design }\end{array}$ & $\begin{array}{l}\text { Cluster randomized, pragmatic and adaptive clinical } \\
\qquad \text { trials }[9,28] \\
\text { Retrospective and prospective observational studies } \\
\text { with extensive and big data [9] }\end{array}$ & Clinical trials and decision analytic modeling [7] \\
\hline $\begin{array}{c}\text { Study } \\
\text { Classification }\end{array}$ & $\begin{array}{l}\text { Methods based on existing evidence [such as systematic review and } \\
\text { decision analysis for treatment comparisons] and new evidence } \\
\text { generating methods [including observational cohort and case-control } \\
\text { studies, as well as randomized clinical trials focusing on comparative } \\
\text { effectiveness [32] } \\
\text { Classified as Clinical Outcome Research in the past [2] }\end{array}$ & Health Economics Studies [6] \\
\hline
\end{tabular}




\section{Perspectives of Experts on Efficiency Studies, Comparative Effectiveness and Cost-Effectiveness Research}

Considering the fact that nursing is an evidence-based discipline, and all of these three studies play an important role in evidence production, there should be a focus on the studies providing opportunities to produce accurate evidence in a comparative effectiveness or cost-effectiveness manner (P.No. 1, 2, 3 and 6). These studies possess high importance and offer applicable solutions as appreciated and valuable evidence that is capable of implementing an intervention with comparative accuracy and lower cost (P.No. 2 and 4).

\section{Ideology of Experts About Nursing Research Priorities}

Demonstrating the cost-effectiveness or cost-effectiveness of nursing, especially registered nursing is an imperative (P.No. 5, 6 and 7). Efficacy, comparative effectiveness, cost-effectiveness, or cost benefit of different implementations, interventions and nursing cares are appropriate priorities for nursing research (P.No. 1). Also, nursing beyond the acute care seems necessary (P.No. 5). Therefore, a wide range of actions can be mentioned for research conductions. For example, music therapy, heat/cold therapy, mental imagery, massage, etc. and comparing modern and traditional practices are notable (P.No. 1 and 2).

\section{Perspectives of Experts on Obstacles and Strategies in Conducting Effectiveness Research}

Effectiveness studies have considered throughout the world alongside efficacy studies (P.No. 5), but in Iran, despite the wide range of feasible research methods, yet they are not considered enough (P.No. 2), Which results due to the existing obstacles leading to obscurity and limited conducting of effectiveness studies, or even insufficient quality of conducted studies (P.No. 1). The mentioned obstacles, included lack of participation or inadequate power of nurses in healthcare policymaking (P.No. 3 and 6), inter and intradisciplinary conflicts or lack of cooperation (P.No. 1), unknown influence of journals and editors on research (P.No. 6), research criticizing efficaciously by stringent controls (P.No. 6 and 7), lack of research outcomes influencing the practice (P.No. 1), staff shortage either faculty members or clinical nurses (P.No. 3)and financial and time limitations (P.No. 1). “... In many medical universities, the lack of appropriate funding and, more importantly, the lack of time lead to less tendencies to conduct these types of studies timeconsuming studies. ... Faculty members are busy with educational duties, so they do not have enough time to conduct these studies or because of the academic years increase in postgraduate students, such studies are not welcomed by colleagues or students. (P.No. 1)." The suggested strategies to reduce the existing obstacles, included providing clinical nursing specialties, Doctor of Nursing practice [DNP] and nurse practitioners, to achieve more power and position in healthcare (P.No. 2), making interests on studying health management alongside clinical services (P.No. 3) and providing information and support among colleagues (P.No. 1 and 4),

\section{Ideology of Experts about Motivating Factors to Conduct Effectiveness Studies}

In order to motivate nursing researchers to conduct effectiveness studies, it was recommended as necessary to increase the level of professional independence in nursing and raise the interdisciplinary coordination and partnership, which requires time and effort for nursing to reach its main position (P.No. 1 and 2). Other mentioned motivators included providing enough time and budget (P.No. 1), receiving support and information from colleagues (P.No. 1 and 4), more training in health economics and better collaboration with health economists [P.No. 5 and 7], and leading research projects and theses to effectiveness methodologies by nursing professors to make the administration context managerially (P.No. 3). "I think these studies would be suitable for $\mathrm{PhD}$ level study not undergraduate and masters as they will take a long time and require expertise and training not available at undergraduate level (P.No. 5)." The importance of effectiveness research could be identified by the implementation of the theses (P.No. 1-7). Also training workshops (P.No. 4) and qualitative methods (P.No. 2), emphasized on theses conductions. Despite this importance, research projects with more feasibility and less time limitations could make better research outcomes in effectiveness scope (P.No. 3).

\section{The Role and Importance of Effectiveness Studies in Nursing Professional Development}

Initially nursing professional development needs to be studied more and deeply (P.No. 4). In spite of this necessity, conducting effectiveness studies, can lead to nursing professional development if their outcomes are used in practice to solve nursing care problems (P.No.1). These projects improve the quality of nursing care, which is the main fundamental feature of service providing professions such as nursing (P.No. 3, 6 and 7). Otherwise conducting effectiveness studies because of their possible distinctions or compulsory being, without interest and lack of adequate regulatory standard monitoring systems, reduces the motivation to use the results in practice (P.No. 1), Which is modified by ethical considerations, creation of advisory groups in health centres for researchers and assessment of clinical trials conducting process that can increase the quality of studies (P.No. 1). On the other hand, it should be noticed that effectiveness may be well represented, but there is a threat about weak point of alternative models which tends to need further exploration and search despite the proven positive results (P.No. 5). 
Conducting such studies can express the profession, especially if they are published in valid journals (P.No. 2). Definitely there is no limitation for effective studies publication if they are conducted in a high quality with powerful research designs and well reported (P.No. 1-7). Among these three types of research, it seems that comparative effectiveness is preferable because of tangible evidence production, but the quality of study determines the publication priorities than methodology itself (P.No. 1-4). Publishing these types of strong studies in Iranian nursing journals can validate them, too (P.No. 4). Therefore, conducting more powerful studies by nursing professors can provide an opportunity to improve clinical conditions and create science production settings over time (P.No. 6 and 7).

\section{Discussion}

This study was conducted to determine a new vision to efficacy, comparative effectiveness and cost-effectiveness research in nursing. For this purpose, an integrative review in combination with Delphi technique was conducted. The emphasized and important role of efficacy and effectiveness research in producing clinical evidence $[6,13,14,16,17]$, mentioned by nursing experts, considers the evidence-based nursing values. So, it is an imperative to transfer knowledge and evidence to practice [4], which results in leading the research to real practice settings as clinical outcomes research. Other possible results include making strong and reliable evidence, conducting any type of research considering the needed priorities for each nation based on health policies and validating the existing body of knowledge or making new knowledge infrastructures. The integrative review indicated that evidence made by efficacy; comparative effectiveness and cost-effectiveness research are complementary to each other, so more training workshops are needed to make theoretical sensibilities in nursing research. The efficacious intervention in an Ideal, selective and controlled setting $[6,16,17]$ should be translated to a real-world setting to prove their effectiveness $[6,13,14,16,17]$ in comparison to the routine care $[8,13,14,16,31]$ in real community populations $[13,14,16]$ with the least possible exclusion criteria [17]. This is a research process to confirm evidence and make them applicable in nursing practice as evidence-based nursing cares.

The patient-centred evidence resulted from comparative effectiveness research $[3,16,21,22,25]$ can increase the cost, because it considers the effectiveness independently without noticing its costs [19]. While increased costs of healthcare services which results in financial burden for both patients and their families and the government itself, makes the healthcare policies to determine effective evidence with lower costs; that is also mentioned by nursing experts. So, using cost-effectiveness analysis is indeed to reduce the healthcare costs $[7,19,31]$. But the usefulness of comparative effectiveness research is agreed [15], and in serious diseases even cost-effectiveness research recommend the effective intervention without considering its costs while this is vice versa in less serious diseases and costs of intervention is prior to their effectiveness [19]. So, everything about making clinical evidence depends on the purpose of researcher and existing policies, also efforts on nursing professional development with increased influencing power on healthcare policies are noticeable. Nursing profession as an independent discipline needs its own strong body of knowledge. As expectations increase for comparative effectiveness research, more gaps appear in body of knowledge and research infrastructures that should be addressed in order to achieve informed decisions and better outcomes [14]. But despite the increased use of this patientcentred research method, controlled trials are more published [33] while the clinical outcome research can provide a stronger body of knowledge in nursing $[2,6]$. Also nursing experts claimed that there are a lot of gaps in nursing, but the existing obstacles fetter these studies. In order to modify the research obstacles, it is necessary to introduce methodologies in detail, which will motivate the faculty members, researchers and students conduct more patient-centred research to make strong body of knowledge for nursing. Therefore, there is a need for standard rules and monitoring systems to conduct high quality studies. Moreover, the effort to strengthen the nursing profession tends to take part in healthcare policy making. Generally determining that which evidence-based intervention, in whom and where is more effective [9], needs more patient involvement in the study [21], according to the community drive, healthcare policies and stakeholders' penetration [9]. And it totally is dependent to the purpose of knowledge translation to practice, because inter and intra-disciplinary collaborations guarantee the research support, funding and evidence-based nursing practice. Yet the least information of nursing experts about the existing differences between efficacy, comparative effectiveness and costeffectiveness research is a challenging issue. And it is still possible to use these two words mistakenly [6]. Therefore, providing information especially for faculty members and nursing journals is so imperative.

\section{Limitations}

The study limitations include lack of access to some databases, limited access to full text of all papers, failure to achieve sufficient with methodological-focused approaches especially in efficacy scope and emerging effectiveness studies in health and nursing in recent decade since 2009. In order to reduce the impact of limitations abstract only papers were reviewed, to prepare their full text if they were appropriate to be enrolled in the integrative review, but none met the eligibility criteria. Instead, the editorials 
and reports which emphasized on methodologies enrolled to the review.

\section{Conclusion}

The efficacy and effectiveness research are important in producing complementary evidence to improve patient care outcomes. Recently, due to the need for comprehensive and accurate information to be more applicable in clinical practice, comparative effectiveness research is more considered and seems to be more important across the world. The effectiveness outcomes origin in the real clinical practice settings and can be extracted using diverse study designs depended on research question and aims. Therefore, the efficacious implementations or interventions should be studied for their effectiveness in real-world settings to become applicable. The obtained evidence needs to be reviewed to make a body of knowledge. The health policies should provide opportunities to test the new knowledge in implementation research in practice. The main conclusion of completing this research process leads to reduce the gap between theory and practice in nursing and its professional development. In spite of the increased consideration to effectiveness research, both in terms of comparative effectiveness and cost-effectiveness, still efficacy studies are more welcomed than effectiveness studies in Iran which demonstrates a controlled impact of an intervention in an ideal setting which is not necessarily applicable in real-world settings. But according to the economic constraints and the high costs of health services, cost-effectiveness studies are increasingly considered in Iran; because costeffectiveness research, determines both costs and effectiveness of two or more interventions correspondingly.

\section{Funding/Support}

Tabriz University of Medical Sciences, Tabriz, Iran provided facilities and supported this project.

\section{Acknowledgment}

We would like to acknowledge the nursing experts who participated in the study and the journals staff who referred the e-mails to their editors in chief in our follow ups.

\section{Conflict of Interests}

None of the authors has any conflict of interest to declare.

\section{References}

1. Bryant-Lukosius D, DiCenso A, Browne G, Pinelli J (2004) Advanced practice nursing roles: Development, implementation, and evaluation. Adv Nurs 48(5): 519-29.

2. Goss CH, Tefft N (2013) Comparative effectiveness research - What is it and how does one do it? Paediatr Respir Rev 14(3): 152-6.

3. Tunis SR, Clarke M, Gorst SL, Gargon E, Blazeby JM, et al. (2016) Improving the relevance and consistency of outcomes in comparative effectiveness research. J Comp Eff Res 5(2): 193-205.
4. Hickman LD, DiGiacomo M, Phillips J, Rao A, Newton PJ, et al. (2018) Improving evidence-based practice in postgraduate nursing programs: A systematic review: Bridging the evidence practice gap (BRIDGE project). Nurse Educ Today 63: 69-75.

5. Forbes A (2009) Clinical intervention research in nursing. Int J Nurs Stud 46(4): 557-68.

6. Grove SK, Burns N, Gray JR (2013) The Practice of Nursing Research: Appraisal, Synthesis, and Generation of Evidence ( $7^{\text {th }}$ Edn.)., Elsevier Saunders, pp. 755.

7. Noyes K, Holloway RG (2004) Evidence from Cost-Effectiveness Research. NeuroRx 1(3): 348-55.

8. Stone PW, Cohen C, Pincus HA (2017) Comparative and cost-effectiveness research: Competencies, opportunities, and training for nurse scientists. Nurs Outlook 65(6): 711-7.

9. Price Haywood EG (2015) Clinical Comparative Effectiveness Research Through the Lens of Healthcare Decisionmakers. Ochsner J 15(2): 15461.

10. Whittemore R, Knafl K (2005) The integrative review: Updated methodology. J Adv Nurs 52(5): 546-53.

11. (2018) CASP UK CASP Checklists - CASP - Critical Appraisal Skills Programme.

12. (2018) Casp UK CASP - Critical Appraisal Skills Programme.

13. (2009) Federal Coordinating Council. Report to the President and the Congress on Comparative Effectiveness Research. Washengton, DC: U.S. Department of Health and Human Services.

14. Institute of Medicine of The National Academies. Initial National Priorities for Comparative Effectiveness Research [Internet]. National Academy of Sciences. Washington, DC: THE NATIONAL ACADEMIES PRESS 2009 , pp. 253

15. (2012) Health Biomedical Science \& Society Initiative. Moving Forward with Comparative Effectiveness Research. Aspen Institute. Health Biomedical Science \& Society Initiative.

16. Kim SY (2013) Efficacy versus effectiveness. Korean J Fam Med 34(4): 227.

17. Pagoto SL, Lemon SC (2013) Efficacy vs effectiveness. JAMA Intern Med 173(13): 1262-3.

18. Kirpalani H, Truog WE, D’Angio CT, Cotten M (2016) Recent controversies on comparative effectiveness research investigations: Challenges, opportunities, and pitfalls. Semin Perinatol 40(6): 341-7.

19. Shafrin J (2010) Comparative Effectiveness vs. Cost Effectiveness Research. Healthcare Economist 2.

20. Devine EB, Perfetto E, Pickard AS, Schumock GT, Segal B, et al. (2018) Nine years of comparative effectiveness research education and training: initiative supported by the PhRMA Foundation. J Comp Eff Res 7(2): 167-75.

21. Mullins CD, Abdulhalim AM, Lavallee DC (2012) Continuous Patient Engagement in Comparative Effectiveness Research. JAMA 307(15): 15878.

22. Knottnerus JA, Tugwell P (2018) Comparative effectiveness research requires competitive effectiveness. J Clin Epidemiol 94: v-vi.

23. Safdar NM, Siegel E, Erickson BJ, Nagy P (2011) Enabling Comparative Effectiveness Research with Informatics. Acad Radiol 18(9): 1072-6.

24. Howie L, Hirsch B, Locklear T, Abernethy AP (2014) Assessing the Value of Patient- Generated Data to Comparative Effectiveness Research. Patients Res 33(7): 1220-8. 
25. Basch E, Aronson N, Berg A, Flum D, Gabriel S, et al. (2012) Methodological standards and patient-centeredness in comparative effectiveness research: The PCORI perspective. JAMA 307(15): 1636-40.

26. Patel I, Rarus R, Tan X, Lee E, Guy J, et al. (2015) Investigation of comparative effectiveness research in Asia, Europe, and North America. Indian J Pharmacol 47(6): 585.

27. Naik AD, Petersen LA (2009) The Neglected Purpose of Comparative-Effectiveness. N Engl J Med 360(19): 1929-31.

28. Sox HC, Goodman SN (2012) The Methods of Comparative Effectiveness Research. Annu Rev Public Health 33(1): 425-45.

29. Conn VS, Ruppar TM, Phillips LJ, Chase JD (2012) Using meta-analyses for comparative effectiveness research. Nurs Outlook 60(4): 182-90.

\section{ISSN: 2574-1241}

DOI: 10.26717/BJSTR.2021.40.006475

Samaneh Alizadeh. Biomed J Sci \& Tech Res

This work is licensed under Creative

Commons Attribution 4.0 License

Submission Link: https://biomedres.us/submit-manuscript.php
30. Atkins D, Kupersmith J (2010) Implementation Research: A Critical Component of Realizing the Benefits of Comparative Effectiveness Research. Am J Med 123(12): e38-45.

31. Bensink ME, Eaton LH, Morrison ML, Cook WA, Curtis RR, et al. (2013) Cost effectiveness analysis for nursing research. Nurs Res 62(4): 279-85.

32. Gray EA, Thorpe JH (2015) Comparative effectiveness research and big data: Balancing potential with legal and ethical considerations. J Comp Eff Res 4(1): 61-74.

33. Hester LL, Poole C, Suarez EA, Der JS, Anderson OG, et al. (2017) Publication of comparative effectiveness research has not increased in high-impact medical journals, 2004-2013. J Clin Epidemiol 84: 185-7.

BIOMEDICAL
RESEARCHES $\quad \begin{aligned} & \text { Assets of Publishing with us } \\ & \text { - Global archiving of articles }\end{aligned}$

